Research Paper

International Journal of Biological Sciences

ISSN 1449-2288 www.biolsci.org 2008 4(3):169-175

CIvyspring International Publisher. All rights reserved

\title{
Difierences in Trabecular Bone of Leptin-Deficient ob/ob Mice in Response to Biomechanical Loading
}

\author{
Hansjoerg Heep, Christian Wedemeyer, Alexander Wegner, Sebastian Hofmeister, Marius von Knoch
}

Department of Orthopaedics, University of Duisburg-Essen, Pattbergstrasse 1-3, 45239 Essen, Germany

* Study was performed at the University of Duisburg - Essen, Deutschland

Correspondence to: Dr. med. Hansjoerg Heep, Department of Orthopaedics, University of Duisburg-Essen, Pattbergstr. 1-3, D-45239 Essen. hansjoerg.heep@uni-due.de; Phone: 0201/4089-2147; Fax: 0201/4089-2722

Received: 2008.04.05; Accepted: 2008.06.13; Published: 2008.06.15

Objective: It is known that bone mineral density (BMD) and the strength of bone is predicted by body mass. Fat mass is a significant predictor of bone mineral density which correlates with body weight. This suggests that body fat regulates bone metabolism first by means of hormonal factors and second that the effects of muscle and loading are signaling factors in mechanotransduction. Leptin, a peptide hormone produced predominantly by white fat cells, is one of these hormonal factors. The aim of this study was to investigate and measure by micro-CT the different effects of weight-bearing on trabecular bone formation in mice without the stimulation of leptin.

Results: Animals with an ad-libitum-diet (Group A) were found to increase body weight significantly at the age of six weeks in comparison with lean mice (Group B). From this point on, the difference increased constantly. At the age of twenty weeks the obese mice were almost twice as heavy as the lean mice. Significant statistical differences are shown between the two groups for body weight and bone mineral density. Examination of trabecular bone (BV/TV, trabecular number (Tb.N.), trabecular thickness (Tb.Th.)) revealed that the only statistically significant difference between the two groups was the Tb.N. for the proximal femur. High weight-bearing insignificantly improved all trabecular bone parameters in the obese mice. Compared with the control-diet Group B, the BV/TV and Tb.N. were slightly higher in the controlled-diet Group A, but not the Tb.Th.. However, correlation was found between Tb.N. and BMD on the one hand and body weight on the other hand.

Conclusion: biomechanical loading led to decreased bone mineral density by a decrease in the number of trabeculae. Trabecular thickness was not increased by biomechanical loading in growing mice. Decreased body weight in leptin-deficient mice protects against bone loss. This finding is consistent with the principle of light-weight construction of bone. Differences in cortical and trabecular bone will be examined in later studies. It is not possible to conclude that these results also apply to human beings.

Key words: Bone mineral density, leptin, biomechanical loading, micro-CT, mice

\section{Introduction}

It is known that bone mineral density (BMD) and the strength of bone is predicted by body mass. Reid et al. found that fat mass alone was a significant predictor of bone mineral density [1]. Fogelholm et al. showed that the bone mineral density in the non-weight bearing bone of the distal radius was more strongly correlated with body weight than bone mineral density in the weight-bearing bones of the hip and spine [2]. In our study we have shown the discrepancy in bone formation in the limbs and spine [3]. This suggests that first body fat regulates bone metabolism by means of hormonal factors, and second the effects of muscle and loading are signaling factors in mechanotransduction $[4,5]$. Leptin, a peptide hormone produced predominantly by white fat cells, is one of these hormonal factors [6-11]. Recent data suggest that leptin may regulate a variety of other physiological processes, such as insulin action [12], hematopoiesis [13], immune function [14], reproduction [15] and angiogenesis [16]. Leptin inhibits appetite; consequently, mice with deficiency of leptin (ob/ob) or its receptor $(\mathrm{db} / \mathrm{db})$ are obese [7]. Takeda et al. and Karsenty described the leptin-dependent central control of bone remodeling via the sympathetic nervous system [11, 17-19]. The sterility of ob/ob mice should increase bone resorption and indeed, osteoclast numbers and parameters of bone resorption increased in ob/ob mice. Nevertheless, leptin-deficient mice have a higher bone mass than wild-type mice and completely correct their high bone mass by intracerebroventricular infusion of leptin at a rate that does not result in any detectable leak of leptin in general circulation [20]. 
However, it is not clear whether leptin is a stimulator or an inhibitor of bone growth in humans. Some investigators noted a positive relationship between serum leptin levels and bone mineral density $[21,22]$, whereas others observed a negative relationship [23, 24]. Furthermore, no associations between serum leptin levels and bone mineral density have been reported $[25,26]$, which further confounds the interpretation of leptin's effect on bone mass. Only a few studies in humans have examined the direct effect of leptin administration on bone mineral density in the early stages of life. Ogueh et al. noted a significant negative correlation between fetal blood levels of leptin and cross-linked carboxyl-terminal telopeptide of Type 1 collagen (a marker of bone resorption). A modest negative correlation was also noted between leptin levels and the concentration of carboxyl-terminal pro-peptide of Type 1 collagen (a marker of bone formation), but the researchers speculated that the overall effect of leptin on fetal bone metabolism was to increase bone mass by decreasing bone resorption [27]. One study reported an increase in bone mass and decrease in bodyweight after long-term leptin therapy in an obese 9-year-old girl with congenital leptin deficiency [28]. This might show the positive effect on bone formation in the early stages of development. Simha et al. concluded that the effect of leptin on bone metabolism may depend on the stage of life in humans [29].

In a few recent reports the animal model was a useful surrogate to investigate the mechanism of leptin. Both leptin and its receptors were found in murine fetal cartilage and bone template, as well as in the growth plate [30]. In addition, leptin increased both proliferation and differentiation of the chondrocyte population of skeletal growth centers in organ cultures [31,32]. All these strongly supported the theory that leptin could stimulate bone growth in the early stages of life.

In general, mechanical loading stress on bones causes tissue deformation within the bone and stimulates the bone to adapt by remodeling to accommodate these demands, ultimately improving resistance to osteoporosis. Forwood et al. hypothesized that strain rate determines osteoblast recruitment in a vivo 4-point bending model in adult rat tibia [33, 34]. While previous studies have shown that bone parameters improved with weight-bearing exercise in normal subjects, we were interested in the co-influence of biomechanical loading on body weight and bone metabolism in subjects with leptin deficiency. There is so far no agreement regarding the positive effect of leptin in the early stages of life.

The ability of three-dimensional micro-computed tomography to detect changes in a rat model was evaluated and compared with dual x-ray absorptiometry for bone mass, and bone histomorphometry for bone mass [35-41].

The aim of this study was to investigate the differential effects of weight-bearing on trabecular bone formation in mice without the stimulation of leptin.

\section{Materials and Methods}

Animals

C57BL/6J-Lep ${ }^{o b}$ (ob/ob) female mice were received from the Janvier Laboratory (Le Genest St Isle, France) at the age of five weeks. The animal experiment was approved by the University`s ethics committee and the local authorities according to the official guidelines.

The effects of dietary restriction in ob/ob and wild-type mice has been described in several studies [42-44]. The animals were housed one per cage with access to water ad libitum and a standard rodent diet (8640 Harlan Teklad 22/5[W]; Harlan Teklad, Madison, WI, USA) containing $1.13 \%$ calcium and $0.94 \%$ phosphorus. The animals were maintained under conditions of a twelve-hour light and dark cycle with the light switched on at 6.00 a.m.. Food intake and body weight were recorded daily. There were two experimental groups divided according to the provision of food. Group A included $20 \mathrm{ob} / \mathrm{ob}$ mice with access to food ad libitum, the other $20 \mathrm{ob} / \mathrm{ob}$ mice in Group B received a limited amount of food (6 gr. each day). All the animals were euthanized by mechanical procedure at the age of twenty weeks.

\section{Micro-CT}

A high resolution micro-CT (SkyScan 1072, Aartselaar, Belgium) was used to perform qualitative and quantitative analysis of the hip and knee. All samples were scanned by a commercially available microcomputed tomographic scanner at the Department of Cardiology of the West German Heart Centre at the University of Duisburg-Essen.

\section{Technical specifications of the micro-CT}

The micro-CT system is based on a scanner developed for high-resolution imaging (up to $4 \mu \mathrm{m}$ cubic voxels) of sample sizes up to $2 \mathrm{~cm}^{3}$. The scanner uses a field $x$-ray tube with an $8 \mu \mathrm{m}$ spot-seize and expected lifetime of $>10,000$ hours. The tube is operated at between 20 and 100 kiloelectron volts and a current of up to 100 micro amperes. For scanning, the samples are placed between the microfocus X-ray source and a Charge-Coupled-Device (CCD) detector (matrix size: $1024 \times 1024$ pixels, field of view: $25 \mathrm{~mm}^{2}$ ). In order to prevent samples from moving during 
scanning, the limbs are placed in a tightly fitting rigid plastic tube. In the scanner's chamber the specimens are placed on a stack of computer-controlled precision stages which are rotated in equiangular steps of $0.9^{\circ}$ around an angle of $180^{\circ}$. When the object is placed between the X-ray source and the CCD-detector, the cone-beam of $X$-rays passes the object and then hits the CCD-detector producing 2D-X-ray images. A personal computer is used to control the scanner and store the CCD image data recorded at each angle of view during the scanning process.

\section{Tomographic image reconstruction}

The X-ray projection data of the scanned samples are then submitted to the resident reconstruction program (Cone-beam Reconstruction, Skyscan, Aartselaar, Belgium), which is based on a Feldkamp filtered back projection algorithm [45] resulting in a volume image of up to 10,243 voxels, each cubic voxel being 4-19 $\mu \mathrm{m}$ on one side, depending on how much of the specimen has to be imaged.

\section{Cancellous bone assessment by micro-CT}

Three regions of interest (ROIs) from the proximal femur and tibia were selected for structural analysis of the cancellous bone. A cubic region of $0.5 \times$ $0.5 \times 0.5 \mathrm{~mm}^{3}$ in the metaphysis of the tibia was adjacent to (1mm away from) the growth plate and femoral head. Bone volume ratio (BV/TV) was calculated by adding the number of voxels representing mineralized trabecular bone divided by the total volume, and expressed as a percentage. Trabecular thickness (Tb. Th) and trabecular number (Tb.N) were based directly on the 3-D data using medial axis transformation and distance transformation.

\section{Statistical analysis}

Data were analyzed and assessed using SPSS software (version 15.0; SPSS Institute Inc, Chicago, USA). Descriptive statistics of all variables were determined including the mean and standard deviation of each group. The difference of all parameters between the two groups was assessed by the Student's t-Test because all parameters (were normally distributed which was tested with the Kolmogorov Smirnov test). Pearson's correlation coefficient was used to assess the relationship between all the trabecular bone parameters of femur and tibia. A value of $p \leq 0.05$ was considered to be statistically significant.

\section{Results}

No death or health deterioration occurred during this study. The body weight at each time point in the two groups is shown in Figure 1.

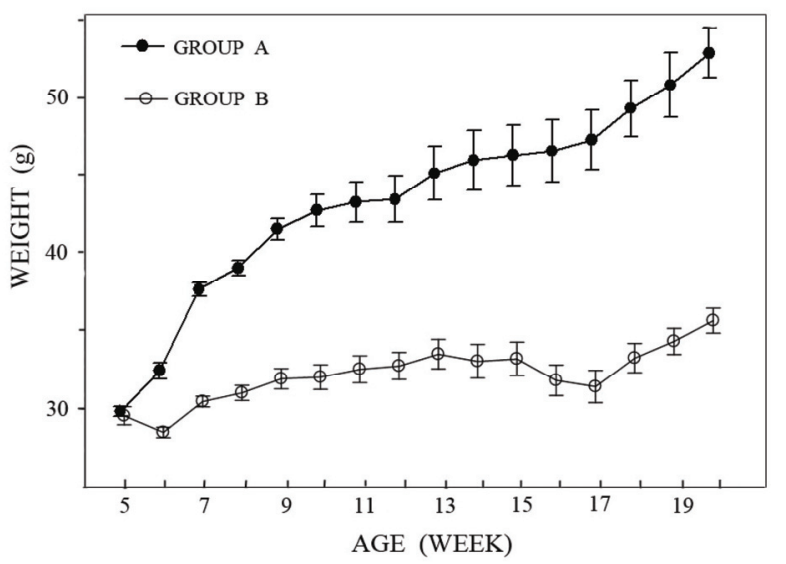

Fig. 1: The curves show the change in body-weight in the two groups. In Group A the animals had an ad-libitum-diet with a body weight over 50 grams after 20 weeks, the animals in Group $\mathrm{B}$ a controlled diet with a body weight over 35 grams after 20 weeks. Inter-group difference was already significant at the age of six weeks $(\mathrm{p}<0.05)$.

Animals with an ad-libitum-diet (Group A) were found to increase body weight significantly at the age of six weeks in comparison with the lean mice (Group B). From this time point on, the difference increased constantly. At the age of twenty weeks the obese mice were almost twice as heavy as the lean mice.

Micro-CT measurements were obtained for assessment of the morphological changes in the two groups (Fig. 2).

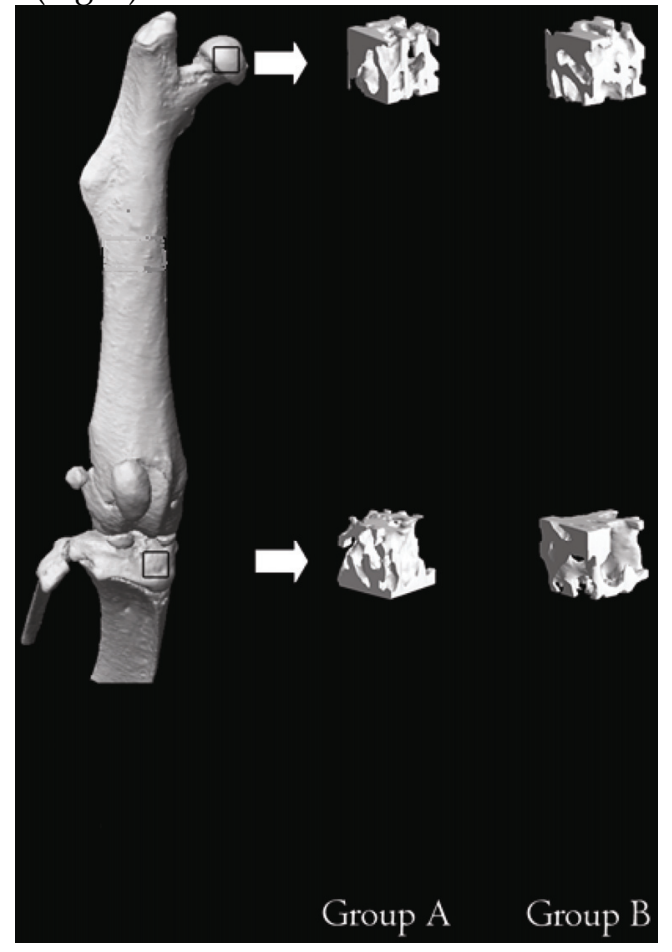

Fig. 2: Three-dimensional images of all the ROIs of the mice in Groups A and B at the age of 20 weeks. The upper frame is the 
ROI of the proximal femur and the below frame the ROI of the proximal tibia.

Statistically significant differences in body weight and bone mineral density between the two groups are shown in Table 1.

Table 1: Statistically significant differences between the ad-libitum-diet Group A and controlled-diet Group B for bone mineral density $(B M D)$ and body weight $(p<0.05)$ at age of 20 weeks.

\begin{tabular}{|c|c|c|c|c|}
\hline Group & $\begin{array}{c}\text { BMD } \\
\text { mean }\end{array}$ & SD & $\begin{array}{c}\text { Weight } \\
\text { (grams) }\end{array}$ & SD \\
\hline mean & \\
\hline $\begin{array}{c}\text { Group A (n=20) } \\
\text { (diet ad libitum) }\end{array}$ & 2.57 & 0.147 & 52.53 & 6.36 \\
$\begin{array}{c}\text { Group B (n=20) } \\
\text { (control diet) }\end{array}$ & 2.68 & 0.138 & 35.65 & 3.50 \\
\hline P value & \multicolumn{2}{|c|}{0.022} & \multicolumn{2}{|c|}{$<0.001$} \\
\hline
\end{tabular}

Examination of trabecular bone (BV/TV, trabecular number (Tb.N.), trabecular thickness (Tb.Th.)) revealed that the only statistically significant difference between the two groups was the trabecular number (Tb.N.) for the proximal femur. High weight-bearing insignificantly improved all trabecular bone parameters in the obese mice. Compared with the controlled-diet Group B, the BV/TV and trabecular number (Tb.N.) were slightly higher in the ad-libitum-diet Group A, but not the trabecular thickness (Tb.Th.) for the proximal tibia (Table 2).

Table 2: Cross-section structural geometric properties of the femur and tibia were evaluated using micro-CT. Note: Summary of morphometric characteristics in the two groups which were different in body weight-bearing. "A statistically significant difference was detected between the two groups only in trabecular number (Tb.N.) of the femur $(\mathrm{p}<0.05)$ at age of 20 weeks.

\begin{tabular}{|c|c|c|c|c|c|c|c|}
\hline Position & Group & $\begin{array}{c}\text { BV/TV } \\
(\%)\end{array}$ & SD & $\begin{array}{l}\text { Tb.Th } \\
\text { (mm) }\end{array}$ & SD & $\begin{array}{l}\text { Tb.N } \\
(1 / \mathrm{mm})\end{array}$ & SD \\
\hline \multirow[t]{3}{*}{ Femur } & $\begin{array}{c}\text { Group A } \\
(\mathrm{n}=20) \\
\text { (ad-libitum } \\
\text { diet) }\end{array}$ & 60.66 & 6.13 & 0.094 & 0.0069 & 6.42 & 0.45 \\
\hline & $\begin{array}{c}\text { Group B } \\
(\mathrm{n}=20) \\
\text { (controlled } \\
\text { diet) }\end{array}$ & 62.76 & 6.5 & 0.093 & 0.0075 & 6.76 & 0.55 \\
\hline & P value & \multicolumn{2}{|c|}{0.347} & \multicolumn{2}{|c|}{0.412} & \multicolumn{2}{|c|}{$0.038^{*}$} \\
\hline \multirow[t]{3}{*}{ Tibia } & $\begin{array}{c}\text { Group A } \\
(\mathrm{n}=20) \\
\text { (ad-libitum } \\
\text { diet) }\end{array}$ & 52.75 & 3.94 & 0.094 & 0.0063 & 5.63 & 0.34 \\
\hline & $\begin{array}{c}\text { Group B } \\
(\mathrm{n}=20) \\
\text { (controlled } \\
\text { diet) }\end{array}$ & 54.64 & 7.48 & 0.093 & 0.0084 & 5.90 & 0.52 \\
\hline & P value & \multicolumn{2}{|c|}{0.325} & \multicolumn{2}{|c|}{0.561} & \multicolumn{2}{|c|}{0.058} \\
\hline
\end{tabular}

Correlation was found between trabecular number (Tb.N.) and bone mineral density (BMD) (measured by micro-CT) and body weight (Figs. 3 and $4)$.

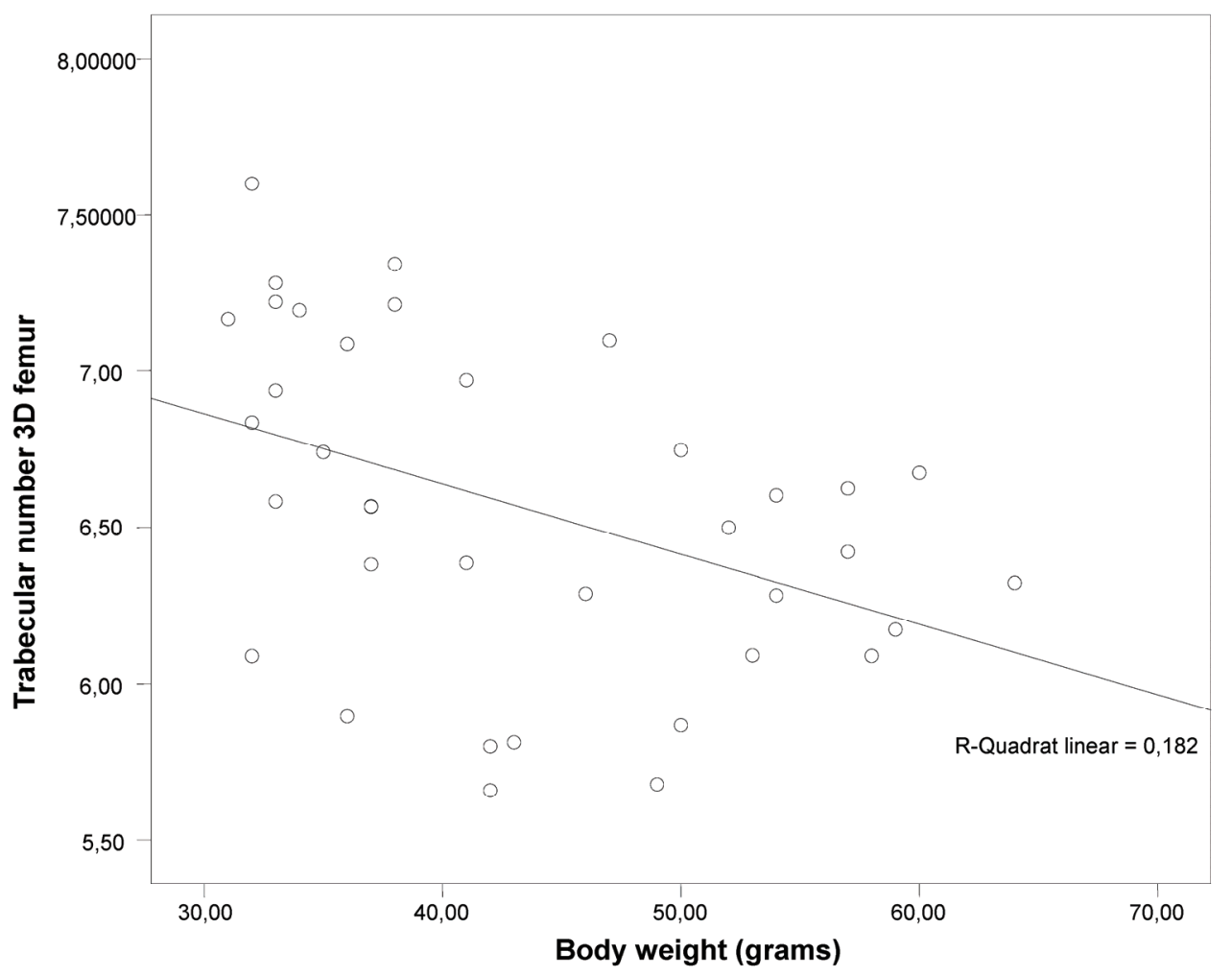

Figure 3: The correlation between trabecular number (Tb.N.) and body weight shows an significant decrease in trabecular number as body weight increases $(\mathrm{p}<0.01)$ in both groups $(\mathrm{n}=40)$. 


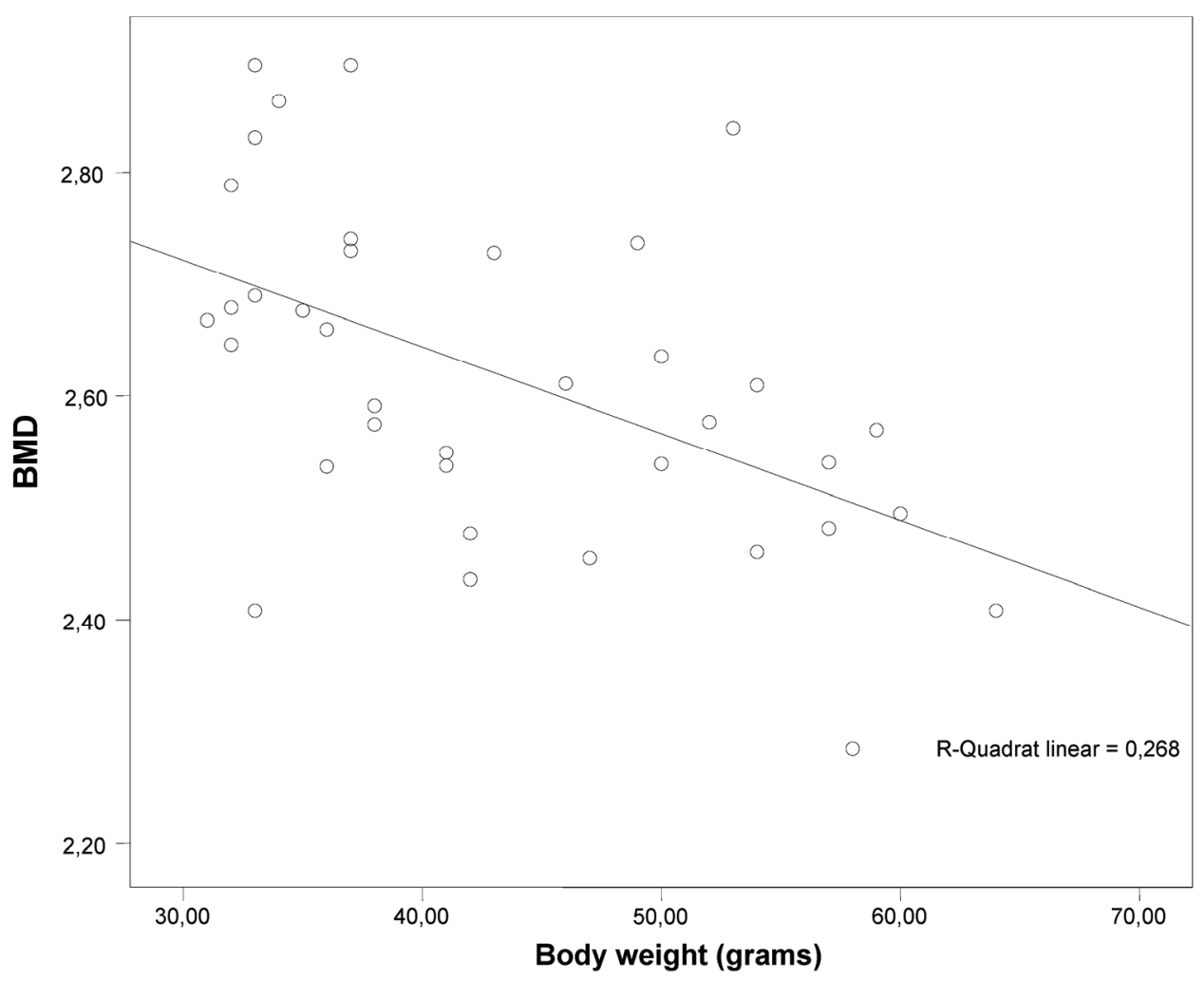

Figure 4: The correlation between bone mineral density (BMD) and body weight shows an significant decrease in BMD as body weight increases $(p<0.01)$ in both groups $(n=40)$.

\section{Discussion}

In our study biomechanical loading led to decrease bone mineral disease and trabecular number in leptin-deficient mice. A great deal of research has confirmed that increased biomechanical loading due to increased body weight contributes to the increased bone dimensions and mass observed not only in our animal model but also in obese humans. At the same time, the increased biomechanical loading due to increased body weight contributed to an increased bone mass as a co-influence. Increased bone mineral density in childhood obesity was therefore revealed both in the weight-bearing limbs and the unloaded arms [46].

Increased loading of long bones produces the greatest mechanical stress on the subperiosteal surface and stimulates bone formation by subperiosteal expansion [47]. A quantitative computertomography (qCT) study in healthy children suggested that weight-bearing and mechanical stresses are important determinants of cortical bone mass, whereas bone mineral density of trabecular bone is influenced by hormonal factors associated with sexual development [48]. A study of bone biomechanics in adult rats with diet-induced obesity showed significantly greater bone strength in the obese rats than in the controls [49]. The cross-sectional geometry and ultimate fracture load of the femur were higher in the obese rats than in the controls. Tromp et al. suggests that the effect of mechanical loading in the rat-with-backpack model mainly occurs at cortical bone sites and not in trabecular metaphyseal bone [35, 36]. The tibial proximal metaphysis is selected for the high cancellous bone compound and is used to explain the effects of disuse, ovariectomy and hormones [50-53]. We could not eliminate the possible effect of other factors on bone mineral density, such as oestrogen. Oestrogen was confirmed to be present in postmenopausal obese females at a relatively higher serum level because adipocytes were a major site of oestrogen production in these subjects $[54,55]$. But the mice in our study were no more than twenty weeks old (in the pubertal stage) and without ovariectomy. Thus, oestrogen due to adipocytes is not a very likely confounding factor in our study.

Leptin deficiency results in low sympathetic tone, and genetic or pharmacological ablation of adrenergic signaling leads to a leptin-resistant high bone mass. B-adrenergic receptors on osteoblasts regulate their proliferation, and a $\beta$-adrenergic agonist decreases the bone mass in leptin-deficient and wild-type mice, while a $\beta$-adrenergic antagonist increases bone mass in wild-type and ovariectomized mice. None of these manipulations affects body weight. Therefore we used 
only leptin-deficient mice in a dietary model. This study of Takeda et al. demonstrates a leptin-dependent neuronal regulation of bone formation with potential therapeutic implications for osteoporosis [18].

In our study, however, there were only insignificant trends in trabecular bone mass between the ad-libitum-diet, leptin-deficient obese mice and the controlled-diet, leptin-deficient mice. In other words, it seemed that increased biomechanical loading due to increased body weight did not contribute to increased bone dimensions in the leptin-deficient subjects. In contrast, Hamrick et al. showed that the endocortical mineralizing surface, serum leptin, body weight, and percentage of body fat in C57BL/ 6 mice all increased between the age of six and twelve months as the activity level of the mice declined [10].

We considered that our results did not negate the conclusion of other researchers regarding the positive effect of biomechanical loading on bone mass, but none of these studies focused on leptin-deficient subjects [56]. The new finding of our study, which focused on the co-influence of biomechanical loading in subjects with leptin deficiency, is that it confirmed the presence of leptin as the pre-condition for a positive trend between loading and bone mass, in contrast to what has been reported in the literature so far [44, 56]. We hypothesized that biomechanical loading due to body weight might be a factor which has led to the contradictory results regarding bone mineral density in studies with mice which were either not known to be deficient in leptin or had inactive leptin receptors.

The data gathered during some research studies appear conflicting or even contradictory. Ducy et al. observed that three- and six-month old obese ob/ob mice, which were deficient in leptin, and diabetic $\mathrm{db} / \mathrm{db}$ mice, which have a mutated and inactive leptin receptor, had higher bone mineral density of trabecular bone associated with a higher mineral apposition rate compared to their wild-type litter-mates [20]. On the other hand, Foldes et al. [57] showed that obese fatty fa/fa rats, which also had a mutated leptin receptor, had a lower bone mass with shorter and lighter femurs compared to their normal litter-mates. Lower femoral bone mineral density and osteocalcin (a marker of bone formation) serum were described in $\mathrm{fa} / \mathrm{fa}$ rats, as well as decreased trabecular bone volume, trabecular thickness and trabecular number, as measured both by micro-CT and histomorphometry [58, 59].

In summary, biomechanical loading led to decreased bone mineral density by a decrease in the number of trabeculae. Trabecular thickness was not increased by biomechanical loading in growing mice.
Decreased body weight in leptin-deficient mice protects against bone loss. This finding is consistent with the principle of light-weight construction of bone. Differences in cortical and trabecular bone will be examined in later studies. It is not possible to conclude that these results also apply to human beings.

\section{Conflict of interest}

The authors have declared that no conflict of interest exists.

\section{References}

1. Reid I.R., et al. Determinants of total body and regional bone mineral density in normal postmenopausal women--a key role for fat mass. J Clin Endocrinol Metab, 1992. 75(1): 45-51.

2. Fogelholm G.M., et al. Bone mineral density during reduction, maintenance and regain of body weight in premenopausal, obese women. Osteoporos Int, 2001. 12(3): 199-206.

3. Heep H., et al. No Adaptions in Bone of Leptin-Deficient ob/ob Mice in Response to Loading. Biomaterialien, 2008. 9: 18-25.

4. Gross T.S., et al. Noninvasive loading of the murine tibia: an in vivo model for the study of mechanotransduction. J Bone Miner Res, 2002. 17(3): 493-501.

5. Warner S.E., et al. Botox induced muscle paralysis rapidly degrades bone. Bone, 2006. 38(2): 257-64.

6. Zhang Y., et al. Positional cloning of the mouse obese gene and its human homologue. Nature, 1994. 372(6505): 425-32.

7. Ahima R.S and Flier J.S. Leptin. Annu Rev Physiol, 2000. 62: 413-37.

8. Hamrick M.W and Ferrari S.L. Leptin and the sympathetic connection of fat to bone. Osteoporos Int, 2008;19(7):905-12.

9. Reid I.R. Relationships between fat and bone. Osteoporos Int, 2008;19(5):595-606..

10. Hamrick M.W., et al. Age-related loss of muscle mass and bone strength in mice is associated with a decline in physical activity and serum leptin. Bone, 2006. 39(4): 845-53.

11. Karsenty G. Convergence between bone and energy homeostases: leptin regulation of bone mass. Cell Metab, 2006. 4(5): 341-8.

12. Boghossian S., et al. Hypothalamic clamp on insulin release by leptin-transgene expression. Peptides, 2006. 27(12): 3245-54.

13. Bhatt R., et al. Long-term kindled seizures induce alterations in hematopoietic functions: role of serum leptin. Epilepsy Res, 2005. 65(3): 169-78.

14. Lam Q.L and Lu L. Role of leptin in immunity. Cell Mol Immunol, 2007. 4(1): 1-13.

15. Popovic V and Casanueva F.F. Leptin, nutrition and reproduction: new insights. Hormones (Athens), 2002. 1(4): 204-17.

16. Kitade M., et al. Leptin-mediated neovascularization is a prerequisite for progression of nonalcoholic steatohepatitis in rats. Hepatology, 2006. 44(4): 983-91.

17. Karsenty G. Leptin controls bone formation through a hypothalamic relay. Recent Prog Horm Res, 2001. 56: 401-15.

18. Takeda S., et al. Leptin regulates bone formation via the sympathetic nervous system. Cell, 2002. 111(3): 305-17.

19. Takeda S. Central control of bone remodeling. Biochem Biophys Res Commun, 2005. 328(3): 697-9.

20. Ducy P., et al. Leptin inhibits bone formation through a hypothalamic relay: a central control of bone mass. Cell, 2000. 100(2): 197-207.

21. Iwamoto J., Takeda T., and Ichimura S. Effect of exercise on tibial and lumbar vertebral bone mass in mature osteopenic rats: bone histomorphometry study. J Orthop Sci, 1998. 3(5): 257-63.

22. Odabasi E., et al. Plasma leptin concentrations in 
postmenopausal women with osteoporosis. Eur J Endocrinol, 2000. 142(2): 170-3.

23. Blum M., et al. Leptin, body composition and bone mineral density in premenopausal women. Calcif Tissue Int, 2003. 73(1): 27-32.

24. Sato M., et al. Association between serum leptin concentrations and bone mineral density, and biochemical markers of bone turnover in adult men. J Clin Endocrinol Metab, 2001. 86(11): 5273-6.

25. Rauch F., et al. Does leptin have an effect on bone in adult women? Calcif Tissue Int, 1998. 63(6): 453-5.

26. Martini G., et al. Influence of insulin-like growth factor-1 and leptin on bone mass in healthy postmenopausal women. Bone, 2001. 28(1): 113-7.

27. Ogueh O., et al. The relationship between leptin concentration and bone metabolism in the human fetus. J Clin Endocrinol Metab, 2000. 85(5): 1997-9.

28. Farooqi I.S., et al. Effects of recombinant leptin therapy in a child with congenital leptin deficiency. N Engl J Med, 1999. 341(12): 879-84.

29. Simha V., et al. Effect of subcutaneous leptin replacement therapy on bone metabolism in patients with generalized lipodystrophy. J Clin Endocrinol Metab, 2002. 87(11): 4942-5.

30. Kume K., et al. Potential role of leptin in endochondral ossification. J Histochem Cytochem, 2002. 50(2): 159-69.

31. Maor G., et al. Leptin acts as a growth factor on the chondrocytes of skeletal growth centers. J Bone Miner Res, 2002. 17(6): 1034-43.

32. Nakajima R., et al. Effects of leptin to cultured growth plate chondrocytes. Horm Res, 2003. 60(2): 91-8.

33. Forwood M.R and Turner C.H. Skeletal adaptations to mechanical usage: results from tibial loading studies in rats. Bone, 1995. 17(4 Suppl): 197S-205S.

34. Forwood M.R., et al. Modification of the in vivo four-point loading model for studying mechanically induced bone adaptation. Bone, 1998. 23(3): 307-10.

35. Ruegsegger P., Koller B., and Muller R. A microtomographic system for the nondestructive evaluation of bone architecture. Calcif Tissue Int, 1996. 58(1): 24-9.

36. Laib A., et al. 3D micro-computed tomography of trabecular and cortical bone architecture with application to a rat model of immobilisation osteoporosis. Med Biol Eng Comput, 2000. 38(3): 326-32.

37. Barou O., et al. High-resolution three-dimensional micro-computed tomography detects bone loss and changes in trabecular architecture early: comparison with DEXA and bone histomorphometry in a rat model of disuse osteoporosis. Invest Radiol, 2002. 37(1): 40-6.

38. Nuzzo S., et al. Quantification of the degree of mineralization of bone in three dimensions using synchrotron radiation microtomography. Med Phys, 2002. 29(11): 2672-81.

39. Ding M., Odgaard A., and Hvid I. Changes in the three-dimensional microstructure of human tibial cancellous bone in early osteoarthritis. J Bone Joint Surg Br, 2003. 85(6): 906-12.

40. Schmidt C., et al. Precision and accuracy of peripheral quantitative computed tomography (pQCT) in the mouse skeleton compared with histology and microcomputed tomography (microCT). J Bone Miner Res, 2003. 18(8): 1486-96.

41. Waarsing J.H., et al. Detecting and tracking local changes in the tibiae of individual rats: a novel method to analyse longitudinal in vivo micro-CT data. Bone, 2004. 34(1): 163-9.

42. Murase T., et al. Dietary diacylglycerol suppresses high fat and high sucrose diet-induced body fat accumulation in C57BL/6J mice. J Lipid Res, 2001. 42(3): 372-8.

43. Hsieh E.A., Chai C.M., and Hellerstein M.K. Effects of caloric restriction on cell proliferation in several tissues in mice: role of intermittent feeding. Am J Physiol Endocrinol Metab, 2005.
288(5): E965-72.

44. Brochmann E.J., et al. Effects of dietary restriction on total body, femoral, and vertebral bone in SENCAR, C57BL/6, and DBA/2 mice. Metabolism, 2003. 52(10): 1265-73.

45. Zhao S., Yu H., and Wang G. A unified framework for exact cone-beam reconstruction formulas. Med Phys, 2005. 32(6): 1712-21.

46. Hla M.M., et al. A multicenter study of the influence of fat and lean mass on bone mineral content: evidence for differences in their relative influence at major fracture sites. Early Postmenopausal Intervention Cohort (EPIC) Study Group. Am J Clin Nutr, 1996. 64(3): 354-60.

47. Zhang $P$ and Yokota H. Effects of surgical holes in mouse tibiae on bone formation induced by knee loading. Bone, 2007. 40(5): 1320-8.

48. Mora S., et al. Age-related changes in cortical and cancellous vertebral bone density in girls: assessment with quantitative CT. AJR Am J Roentgenol, 1994. 162(2): 405-9.

49. Brahmabhatt V., et al. The effects of dietary-induced obesity on the biomechanical properties of femora in male rats. Int J Obes Relat Metab Disord, 1998. 22(8): 813-8.

50. Iwamoto J., Yeh J.K., and Aloia J.F. Differential effect of treadmill exercise on three cancellous bone sites in the young growing rat. Bone, 1999. 24(3): 163-9.

51. Iwamoto J., Yeh J.K., and Takeda T. Effect of vitamin $\mathrm{K} 2$ on cortical and cancellous bones in orchidectomized and/or sciatic neurectomized rats. J Bone Miner Res, 2003. 18(4): 776-83.

52. Zhou H., et al. Anabolic action of parathyroid hormone on cortical and cancellous bone differs between axial and appendicular skeletal sites in mice. Bone, 2003. 32(5): 513-20.

53. Ito M., et al. Differences of three-dimensional trabecular microstructure in osteopenic rat models caused by ovariectomy and neurectomy. Bone, 2002. 30(4): 594-8.

54. Heshmati H.M., et al. Role of low levels of endogenous estrogen in regulation of bone resorption in late postmenopausal women. J Bone Miner Res, 2002. 17(1): 172-8.

55. Khosla S., et al. Relationship of serum sex steroid levels and bone turnover markers with bone mineral density in men and women: a key role for bioavailable estrogen. J Clin Endocrinol Metab, 1998. 83(7): 2266-74.

56. De Souza R.L., et al. Non-invasive axial loading of mouse tibiae increases cortical bone formation and modifies trabecular organization: a new model to study cortical and cancellous compartments in a single loaded element. Bone, 2005. 37(6): 810-8.

57. Foldes J., Shih M.S., and Levy J. Bone structure and calcium metabolism in obese Zucker rats. Int J Obes Relat Metab Disord, 1992. 16(2): 95-102.

58. Picherit C., et al. Isoflavone consumption does not increase the bone mass in osteopenic obese female zucker rats. Ann Nutr Metab, 2003. 47(2): 70-7.

59. Tamasi J.A., et al. Characterization of bone structure in leptin receptor-deficient Zucker (fa/fa) rats. J Bone Miner Res, 2003. 18(9): 1605-11. 